\title{
Trends in studies of edge influence on vegetation at human- created and natural forest edges across time and space ${ }^{1}$
}

\author{
Caroline M.A. Franklin, Karen A. Harper, and Madeline J. Clarke
}

\begin{abstract}
Forest edges, or boundaries between adjacent ecosystems, play important ecological roles. Both anthropogenic and natural forest edges affect vegetation while contributing to landscape heterogeneity. The recent proliferation of studies on vegetation at edges suggests that a comprehensive review of global edge studies is timely. We reviewed the literature on forest edges to identify trends in edge studies over time, determine types and localities of studied edges, and compare findings on edge influence. We found 446 studies conducted in 55 different countries that considered edge influence on vegetation structure and (or) composition. Research on vegetation at anthropogenic edges has increased and expanded geographically, but studies are still scarce in some areas and at natural forest edges. Forest edges were generally characterized by greater species diversity and nonnative species abundance than interior forest. Distance of edge influence on vegetation extended furthest at tropical anthropogenic forest edges compared with other edge types and locations. Edge influence on responses caused by indirect effects of edges generally extended further into the forest than edge influence on responses related to forest structure. Our findings indicate that vegetation characteristics differ between edge and forest types and should be considered in the sustainable management of heterogeneous forested landscapes.
\end{abstract}

Key words: anthropogenic edge effects, edge influence, forest edge, fragmentation, natural disturbance.

Résumé : Les bordures de forêt, ou les frontières entre des écosystèmes adjacents, ont des rôles écologiques importants. Les bordures de forêt, tant anthropiques que naturelles, ont un effet sur la végétation tout en contribuant à l'hétérogénéité du paysage. La prolifération récente des études sur la végétation dans les bordures indique qu'une revue approfondie de l'ensemble des études sur les bordures est opportune. Nous avons fait une revue de la littérature sur les bordures de forêt dans le but d'identifier les tendances des études sur les bordures avec le temps, de déterminer les types et la localisation des bordures qui ont été étudiées et de comparer les résultats sur l'influence des bordures. Nous avons trouvé 446 études réalisées dans 55 pays différents qui portent sur l'influence des bordures sur la structure ou la composition de la végétation. La recherche sur la végétation dans les bordures anthropiques a augmenté et s'est étendue géographiquement, mais les études sont encore rares dans certaines régions ainsi que dans les bordures de forêt naturelles. Les bordures de forêt sont généralement caractérisées par une plus grande diversité d'espèces et abondance d'espèces exotiques que l'intérieur de la forêt. La distance sur laquelle la bordure influence la végétation est plus grande dans le cas des bordures de forêt anthropiques en milieu tropical comparativement aux autres types et localisations de bordures. L'influence des bordures sur les réactions dues à des effets indirects des bordures s'étend généralement plus loin dans la forêt comparativement à l'influence des bordures sur les réactions reliées à la structure de la forêt. Nos résultats indiquent que les caractéristiques de la végétation diffèrent selon les types de bordure et de forêt et qu'on devrait en tenir compte dans l'aménagement durable des paysages forestiers hétérogènes. [Traduit par la Rédaction]

Mots-clés : effets des bordures anthropiques, influences des bordures, bordure de forêt, fragmentation, perturbation naturelle.

\section{Introduction}

Forest edges, which are the interfaces between forested and nonforested areas, are integral components of forested landscapes, particularly those fragmented by anthropogenic disturbance such as forest harvesting or agricultural development. A forest edge can be induced by disturbance or inherent because of steep gradients in microclimate, topography, soil type, or geomorphology (Thomas et al. 1979). Whereas forest edges induced by anthropogenic disturbances such as clear-cutting have received a lot of attention due to negative effects on the adjacent forest
(Harper et al. 2005), forest edges induced by natural phenomena such as wildfires and insect outbreaks are less understood. Natural boundaries between adjacent ecosystems are ecologically important, as they may harbour greater species diversity and functional diversity than adjacent ecosystems (e.g., Erdős et al. 2018). Furthermore, natural forest edges can provide unique habitat that acts as refugia for specific plant species (Erdős et al. 2011, 2013, 2019).

Edge studies have been an important part of the history of forest science research since early studies on agricultural edges (Wales 1972; Ranney et al. 1981). Boundaries have become a focus of ecological research because of their high diversity (Kellman

Received 30 June 2020. Accepted 18 October 2020.

C.M.A. Franklin,* K.A. Harper, and M.J. Clarke. Biology Department, Saint Mary’s University, 923 Robie St., Halifax, NS B3H 3C3, Canada.

Corresponding author: Caroline M.A. Franklin (email: carolinemafranklin@gmail.com).

*Present address: Department of Biology, Wilfrid Laurier University, 75 University Ave. W., Waterloo, ON N2L 3C5, Canada.

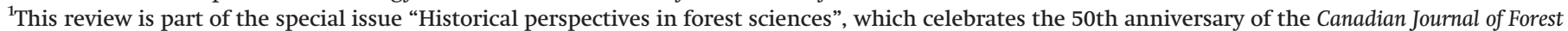
Research.

Copyright remains with the author(s) or their institution(s). Permission for reuse (free in most cases) can be obtained from copyright.com. 
et al. 1994), unique qualities (e.g., Sala and Maestre 2014; Paiva et al. 2015), and sensitivity to climate change (Holland 1988; Risser 1993). In recent decades, forest edge studies on harvested edges have informed forest management and conservation (e.g., Laurance 1991). A better understanding of natural forest edge characteristics would also be beneficial for ecological management and conservation, as such knowledge is increasingly being applied to natural-disturbance-based ecosystem management (Stockdale et al. 2016; De Grandpré et al. 2018). Estimating and predicting transition widths and their dynamics are important for understanding effects of management activities on forest ecosystems, predicting impacts of climate change, and identifying priority areas for conservation.

The proliferation of field-based studies on vegetation at forest edges in the past 15 years, particularly in previously understudied regions such as Asia (Suzuki et al. 2013; Hauck et al. 2014) and Africa (Sassen and Sheil 2013; Malcolm et al. 2017), suggests that a more comprehensive global synthesis is timely. Cadenasso et al. (2003) noted that empirical research necessary for predictive quantitative models lagged behind conceptual work. Systematic review is an important tool for evaluating conservation evidence, identifying knowledge gaps and methodological inconsistencies, supporting environmental decision-making, and focusing research priorities (Pullin and Knight 2009; Haddaway and Pullin 2014). A review of fragmentation studies found that most empirical research was conducted in temperate forests in Europe and the Americas, and recommended greater understanding of underlying mechanisms (Fardila et al. 2017).

At forest edges, gradients in wind, light, and other factors from the nonforested area influence vegetation in the adjacent forest through structural damage, production of deadwood, and increased growth or regeneration (Chen et al. 1992; Laurance et al. 1998; Harper and Macdonald 2002; Harper et al. 2005). Direct and immediate effects of edge creation, including tree mortality and altered canopy cover, are termed primary responses that can cause indirect effects of edge creation, which are known as secondary responses (e.g., understory abundance and species composition) (Harper et al. 2005). Edge influence occurs when there is a detectable difference in a given response variable between the forest edge and adjacent forest interior (Harper et al. 2005). Whereas some studies only compare response variables at the edge to those of the forest interior, other studies quantify edge influence by estimating the distance that an effect penetrates into the forest interior, known as the distance of edge influence (DEI). This measure can estimate the area affected by edge influence on a landscape, which can be used in forest management or conservation planning (Laurance 1991). The impact of edges on forest ecosystems may be underestimated without consideration of ecological effects extending into the adjacent forests.

Edge influence varies depending on edge type, forest type, and response variable of interest (Harper et al. 2005). Induced edges are expected to experience greater edge influence than more stable inherent edges that are relatively long-term landscape features. For example, edge influence was more extensive at fire edges than at lake or wetland edges in boreal forests (Harper et al. 2015). Natural edges are believed to be more gradual but complex and variable transition zones as compared with anthropogenic edges (Harper et al. 2004; Hanson and Stuart 2005; Larrivée et al. 2008; Braithwaite and Mallik 2012). Edge influence at anthropogenically induced forest edges is generally greater in tropical and temperate forests than in boreal forests, which are characterized by relatively weak edge influence (DEI typically $<20 \mathrm{~m}$ ) attributed to natural stand-replacing disturbances (Harper et al. 2005, 2015). Regardless of edge origin and forest type, secondary responses (e.g., understory plant species composition) usually exhibit greater edge influence than primary responses (e.g., forest structure) for anthropogenic forest edges (Harper and Macdonald 2002; Harper et al. 2005).
A critical comparison of the estimates of DEI among forest edge studies could suggest potential factors affecting the variability in edge responses. We present a synthesis and development over time of existing literature on the influence of forest edges on plant community responses that not only provides a better understanding of edge influence, but also reveals relevant research and knowledge gaps. Our objectives were to $(i)$ identify trends in the number of edge studies over time for both anthropogenic and natural edges for different continents, (ii) determine the types and localities of edges that have been researched, and (iii) compare previous findings on edge influence. We hypothesized that (i) edge studies have increased in number over time but are still lacking in many developing regions, (ii) edge influence is greater in tropical and temperate forests than in boreal forests, (iii) anthropogenic forest edges exhibit greater edge influence than natural forest edges, and (iv) edge influence has a greater effect on secondary responses than on primary responses.

\section{Methods}

We performed a thorough literature review to obtain published journal articles that considered the structure and (or) composition of vegetation at natural and (or) anthropogenic forest edges. We searched the Web of Science Core Collection, Biological Abstracts, and SciELO Citation Index databases for articles from 1900 to 2019 matching "(Environmental Sciences \& Ecology OR Forestry OR Biodiversity \& Conservation)" in the subject field and "(vegetation OR plant\$ OR flora) AND (edge effect\$ OR edge influence OR ecotone) AND (distance OR width OR depth) AND (forest\$) NOT (nest*)" in the topic field on 11 August 2020. Articles were manually screened for the presence of data related to aboveground vegetation at forest edges.

We used this search to create an edge studies database consisting of articles that considered vegetation response(s) at the forest edge in relation to the forest interior. We particularly wanted to target studies on natural forest edges because literature on vegetation composition and structure at anthropogenic edges has been considered in prior reports (e.g., Harper et al. 2005). Therefore, we used an additional search of the Web of Science database for articles matching “((forest)) AND (edge* OR boundar* OR ecotone) AND (plant OR plants OR vegetation))" in the topic field on 20 October 2018. We also used reference lists and personal collections to seek additional relevant papers. We classified forest edges as natural if they were created by a natural phenomenon or were adjacent to an inherent natural ecosystem and had been unaffected by human activity for at least five decades prior to data collection. Consequently, forest edges adjacent to areas grazed by domestic animals or forest edges maintained by fires intentionally ignited by humans were not considered natural edges.

For our edge studies database, we only included studies that compared vegetation processes, structure, or composition between forest edge and forest interior by quantitatively determining spatial patterns and (or) DEI. Consequently, our review was limited to studies that compared vegetation at forest edges to interior forest and therefore did not consider nonmonotonic responses that are likely to occur along natural edge gradients and have been detected with wavelet analyses (e.g., Franklin and Harper 2016). Articles that reviewed multiple papers, most of which were already included in the subset, were also excluded so as not to repeat the same results more than once. We did not conduct a meta-analysis because of methodological differences in evaluating edge influence.

For each article in the edge studies database, we classified the vegetation response variable as $(i)$ primary (direct edge effect) or secondary (indirect edge effect) and (ii) process, structure, or composition following criteria outlined by Harper et al. (2005). Cases in which a given response variable was investigated for a single species or was examined using a manipulative experiment were 
Fig. 1. Number of published studies $(n=434)$ on vegetation at natural and anthropogenic edges over time. The search was conducted using the Web of Science Core Collection, Biological Abstracts, and SciELO Citation Index databases. Articles that discussed both natural and anthropogenic edges were included in counts for both edge types.

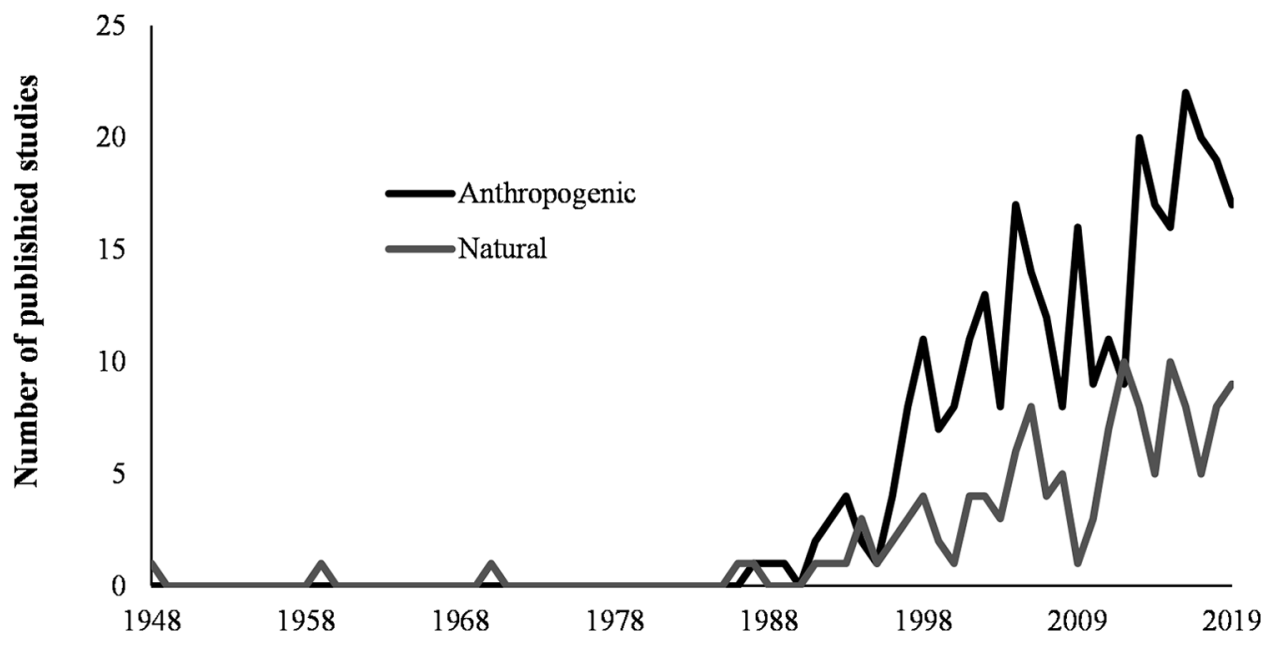

excluded from the synthesis. We noted whether each vegetation response variable was higher, lower, or not significantly different at the edge compared with interior forest. For each study that reported DEI, we also noted the mean DEI for each response variable. DEI estimates were averaged when articles reported ranges. For natural forest edges adjacent to another forest, the "interior forest" was classified as the forest at the lower altitude in the case of altitudinal gradients and as the more closed-canopied forest in the case of nonaltitudinal gradients. To gain an understanding of how edge orientation affects vegetation responses and DEI, articles from the edge studies database were screened for the key words “orient", "aspect", “direct”, and "facing”. Only articles that discussed orientation as it related to vegetation characteristics were noted as those that considered orientation.

\section{Results}

Temporal and geographic trends in forest edge studies

Our literature search resulted in 986 articles (Supplementary Table $S 1^{2}$ ). We excluded 552 articles because they did not consider aboveground vegetation at a forest edge. Of the excluded articles, many focused on fauna (27\%), whereas others did not discuss edges $(16 \%)$, could not be sourced $(16 \%)$, or focused on microclimate $(11 \%)$ and soil characteristics $(6 \%)$. The number of articles that considered vegetation at forest edges $(n=434)$ gradually increased over time, with very few studies before the 1980s followed by a dramatic increase in 1998 (Fig. 1). Although the earliest studies on vegetation at forest edges were at naturally inherent forest edges, there have been fewer studies published on vegetation at natural forest edges than at anthropogenic forest edges since 1996. In the 1990s, the dominant focus of studies was pastures in tropical forests and clearcuts or tree lines in boreal forests but has since shifted to include various edge types (Supplementary Table $S 2^{2}$ ).

Published studies on vegetation at forest edges have been conducted in 58 different countries (Fig. 2). The majority of studies were conducted in North America (36\%), followed by Europe (19\%), Asia (17\%), South America (16\%), Oceania (7\%), and Africa $(<1 \%)$. There were gaps in edge research throughout most of Africa, the Middle East, eastern Europe, and parts of Asia (Fig. 2). Although some of these gaps visible on the map are due to large unforested areas, edge studies are scarce in forested areas in north-central South America, southern South America, Africa, southern Asia, and especially the large region of eastern Europe and northern Asia (including Siberia). In addition, open-canopied forests found in many savanna areas have not been the subject of many edge studies (e.g., in the Middle East). The number of edge studies has remained low in Africa and Oceania but has increased recently in Asia and South America. In Europe, the number of edge studies has fluctuated but has generally been high. Meanwhile, the number of edge studies in North America has been more consistent, with a large peak in the early 2000 s.

\section{Forest edge types and localities}

The final database of comparisons of vegetation structure and (or) composition between the forest edge and forest interior was comprised of 446 studies conducted in 55 different countries from 397 articles (several articles considered different forest edge types) (Supplementary Table $\mathrm{S2}^{2}$ ). The majority of edges (338 of 446) were anthropogenic, whereas there were 89 and 19 studies on natural inherent edges (adjacent to a relatively permanent nonforest ecosystem devoid of human activity) and natural induced edges (created by a natural disturbance), respectively (Table 1).

We classified 17 different natural edge types and more than 11 different anthropogenic edge type categories (Table 1). Of the natural forest edge types, 13 were inherently adjacent to a natural ecosystem (barren, cliff, dune, grassland, meadow, other forest, savanna, shrubland, tree line, tundra, waterbody (e.g., lake), watercourse (e.g., river or stream), and wetland (e.g., bog, mire, or peatland)), and the remaining four were induced by a natural phenomenon (insect outbreak, landslide, lava flow, and wildfire). Altitudinal tree line was the most prevalent adjacent ecosystem in natural forest edge research ( $20 \%$ of studies). Of the induced natural forest edges, wildfire was the most commonly studied edge type (60\%). Nearly one-third (29\%) of anthropogenic edges were induced by harvesting, and some were adjacent to a regenerating plantation. Studies were conducted at harvested edges of various ages. One-quarter (25\%) of anthropogenic edges were created for maintained cropland or pasture. Other anthropogenic edge types were adjacent to old fields, areas affected by fire ignited by humans, wetlands or grasslands altered by human activity, urban areas, roads, and narrow corridors (e.g., seismic and power lines).

\footnotetext{
${ }^{2}$ Supplementary data are available with the article at https://doi.org/10.1139/cjfr-2020-0308.
} 
Fig. 2. Locations of published studies $(n=434)$ on natural edges, anthropogenic edges, and both types of edges from the literature search, which was conducted using the Web of Science Core Collection, Biological Abstracts, and SciELO Citation Index databases. Embedded plots represent trends in the number of edge studies over time for individual continents. The map was created using ArcGIS Pro version 2.5 (Esri, Redlands, Calif., USA) with a base map from Natural Earth (Coastline) and a shapefile from World Wildlife Fund (Terrestrial Ecoregions of the World).

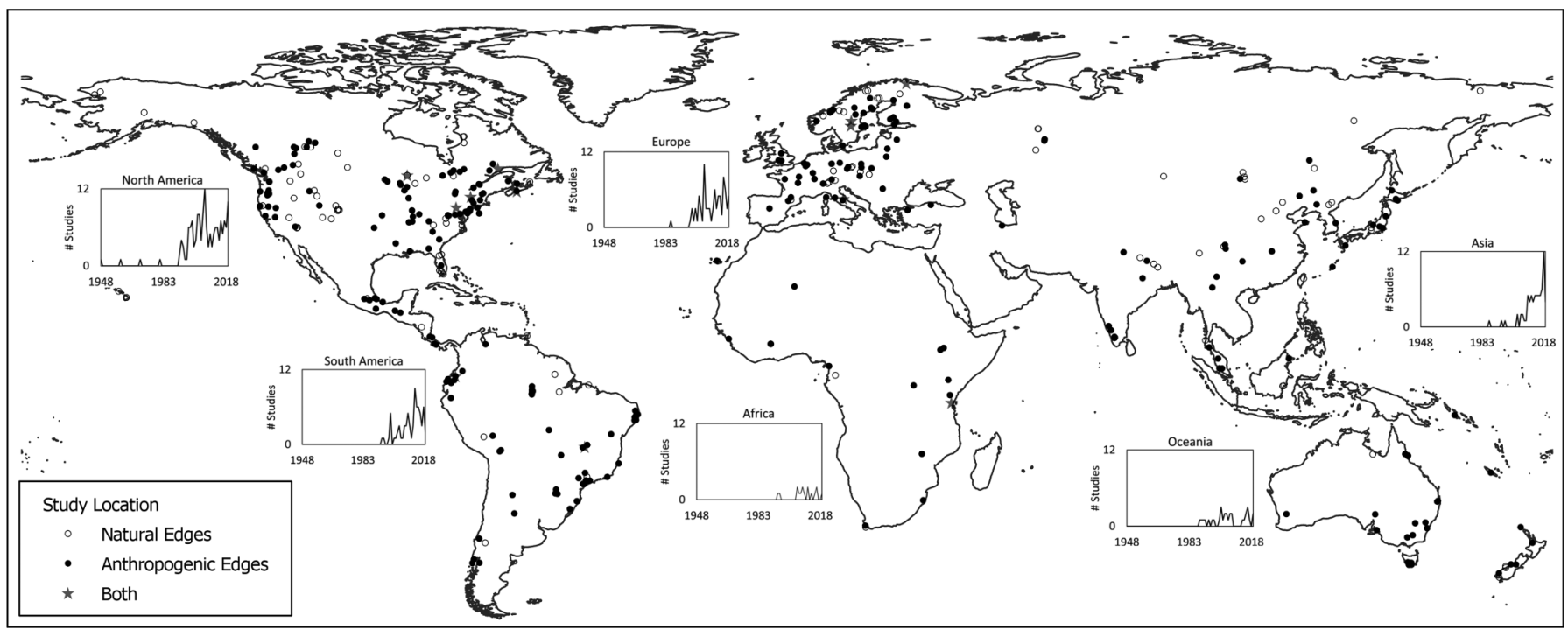

The largest proportion of studies (45\%) was conducted in temperate forests, with $31 \%$ and $21 \%$ of studies in tropical and boreal forests, respectively (Table 1). The remaining 3\% of studies were conducted in mature tropical or temperate plantations, which were bordered by an anthropogenically induced edge. There were more studies on fire, insect outbreak, and younger harvested edges in boreal forest, and on savanna and pasture edges in tropical forest.

When considering edge orientation, 310 studies (70\%) did not control for its effects on vegetation responses, 70 studies (16\%) described only a single orientation (whether by nature of the edge itself or to control for edge orientation), and only 66 studies (15\%) discussed the effects of edge orientation. Of the 66 studies, 43 found that at least one vegetation response or DEI was affected by orientation, and the remaining 23 studies described no effects (Supplementary Table $\mathrm{S}^{2}$ ).

\section{Vegetation responses to forest edges}

In total, 93 different response variables were compared between forest edges and interior forests in at least three studies (Supplementary Table $\mathrm{S}^{2}$ ). Although primary process response variables such as tree mortality and windthrow were generally higher at edges than in interior forest, the resultant primary structure variables, especially responses related to live trees, were lower at edges than in interior forest (Table 2). Dead tree abundance was usually greater at both anthropogenic and natural induced edges, but not at natural inherent edges, as compared with interior forest. Secondary process variables also exhibited higher responses at induced edges, suggesting that processes in general increase following edge creation. Secondary structure and composition response variables were generally higher at edges than in interior forest, except for nonvascular cover, which was more often lower at edges than in interior forest. Species diversity and richness were significantly higher at the forest edge than in the interior forest in $56 \%, 50 \%$, and $32 \%$ of studies at natural inherent, anthropogenic, and natural induced edges, respectively. Nonnative species abundance and richness were higher at the edge than in the interior forest in $93 \%$ and $50 \%$ of studies at anthropogenic and natural inherent edges, respectively, and were not significantly different at natural induced edges. Browse damage was higher at anthropogenic and natural induced edges than in interior forest but had not been documented at natural inherent edges.

There were some notable differences in responses among edge types (Supplementary Table S4 ${ }^{2}$ ). Tree mortality and shrub cover at urban edges were lower than in interior forest rather than higher as at other edge types. Trees were wider but shorter at road edges than those in interior forest. Results on canopy tree density and abundance were mixed, with lower values at clearcut edges compared with interior forest and higher values at cropland and pasture edges. The proportion of responses that were significantly different at the edge than in the forest interior was slightly higher for burn edges adjacent to areas affected by fire caused by human activity $(75 \%)$ than by wildfire (67\%). Linear features also had a higher proportion of significantly different responses at the edge compared with the forest interior for anthropogenic ( $81 \%$ for roads and other human-made corridors) as opposed to natural ( $59 \%$ for watercourses) forest edges.

\section{Edge influence}

In total, 56 studies describing 65 edges estimated DEI for natural (11 studies, 12 edges) and anthropogenic (45 studies, 53 edges) forest edges (Supplementary Table $S 5^{2}$ ). The majority of natural edge studies were conducted in boreal forests (67\%), and we found no studies that considered DEI estimates for natural forest edges in tropical forests. As for anthropogenic edge studies that estimated DEI, $54 \%$ were conducted in temperate forests, followed by $25 \%$ and $21 \%$ in boreal and tropical forests, respectively.

DEI estimates for primary structural response variables were generally lower than those for secondary structure and composition, although there was a lot of variation (Fig. 3; Supplementary Table $S 6^{2}$ ). DEI on vegetation structure and composition ranged from 0 to $75 \mathrm{~m}$ for natural forest edges and to $500 \mathrm{~m}$ for anthropogenic edges. It is difficult to make comparisons among the different edge types because of the lack of studies with similar response variables. DEI for overstory, the only response measured by multiple studies for all edge types (inherent, natural induced, and anthropogenic induced), was greater at anthropogenic edges than at either type of natural edge. Other responses, but not all, extended further 
Table 1. Number of edges studied for natural inherent, natural induced, and anthropogenic edge types in boreal, temperate, and tropical forests, as well as in temperate and tropical plantations (for anthropogenic induced edges only).

\begin{tabular}{|c|c|c|c|c|c|c|}
\hline Edge type & Boreal & Temperate & Tropical & $\begin{array}{l}\text { Temperate } \\
\text { plantation }\end{array}$ & $\begin{array}{l}\text { Tropical } \\
\text { plantation }\end{array}$ & Tota \\
\hline \multicolumn{7}{|l|}{ Natural inherent } \\
\hline Barren & & 1 & & & & 1 \\
\hline Cliff & & 1 & & & & 1 \\
\hline Dune & & 1 & & & & 1 \\
\hline Grassland & 3 & 6 & 8 & & & 17 \\
\hline Meadow & 1 & 2 & & & & 3 \\
\hline Other forest ${ }^{a}$ & 2 & & 1 & & & 3 \\
\hline Savanna & & & 2 & & 1 & 3 \\
\hline Shrubland & & 2 & & & & 2 \\
\hline Tree line & 13 & 5 & 4 & & & 22 \\
\hline Tundra & 3 & & & & & 3 \\
\hline Waterbody & 3 & & 2 & & & 5 \\
\hline Watercourse & 5 & 8 & 5 & 1 & & 19 \\
\hline Wetland & 4 & 7 & & & & 11 \\
\hline \multicolumn{7}{|l|}{ Natural induced } \\
\hline Insect outbreak & 3 & 1 & & 1 & & 5 \\
\hline Landslide & & 1 & & & & 1 \\
\hline Lava flow & & & 2 & & & 2 \\
\hline Wildfire & 5 & 6 & 1 & & & 12 \\
\hline \multicolumn{7}{|l|}{ Anthropogenic } \\
\hline Altered grassland $^{b}$ & & 3 & 1 & & & 4 \\
\hline Altered wetland ${ }^{c}$ & & 4 & & & & 4 \\
\hline Clearcut & 5 & 7 & 3 & 3 & & 18 \\
\hline Young clearcut & 16 & 11 & 3 & 1 & & 31 \\
\hline Intermediate clearcut & 9 & 11 & 1 & & & 21 \\
\hline Old clearcut & 9 & 13 & 6 & & & 28 \\
\hline Cropland & 2 & 27 & 13 & & & 42 \\
\hline Human-made corridor & 4 & 5 & 5 & & 1 & 15 \\
\hline Intentional fire & 1 & 7 & 6 & & & 14 \\
\hline Old field & & 13 & 5 & & & 18 \\
\hline Pasture & 1 & 9 & 33 & & 1 & 44 \\
\hline Plantation & & 1 & 4 & & & 5 \\
\hline Young plantation & & 3 & 1 & & & 4 \\
\hline Old plantation & & 3 & 4 & & & 7 \\
\hline Road & 2 & 15 & 8 & 1 & 2 & 28 \\
\hline Urban & 4 & 11 & 2 & & & 17 \\
\hline Other $^{d}$ & & 9 & 5 & 1 & & 15 \\
\hline Various $^{e}$ & & 7 & 13 & & & 20 \\
\hline
\end{tabular}

Note: Young clearcuts are $\leq 10$ years old, intermediate clearcuts are 11-20 years old, and old clearcuts are $>20$ years old. Young and old plantations are $\leq 20$ and $>20$ years old, respectively. Note that plantation can be the disturbed or forested side of the edge.

${ }^{a}$ Edges bordered distinct forests (interior forest was the side with greater canopy cover).

${ }^{b}$ Grassland was periodically mowed in the last 50 years.

${ }^{c}$ Water tables affected by human activities such as mining or dam creation.

${ }^{d}$ Dam closure, mining activity, military grounds, maintained grass, ski slope, golf course, desertification, insect outbreak in plantation, or unclear.

${ }^{e}$ Edges described as multiple types, including cropland-road, cropland-pasture, cropland-pasture-road, cropland-urban, cropland-old field, pasture-old field, old field-road, pasture-cropland-intentional fire, pasturecropland-plantation, plantation-wetland-road-cropland, and clearcut-pasture-intentional fire-cropland.

into the forest at anthropogenic edges. Some notable exceptions include greater DEI for both types of induced edge compared with natural inherent edges for diversity and lower DEI for lichens at anthropogenic edges than those at natural edges.

Mean DEI across all variables and studies was similar for natural induced and inherent forest edges ( 22 and $25 \mathrm{~m}$, respectively) but was much greater for anthropogenic induced edges $(42 \mathrm{~m})$. Mean DEI increased from boreal to temperate to tropical edges for both natural and anthropogenic induced edges (Fig. 4). However, mean DEI was greater in boreal forest than in temperate forest for natural inherent edges. Mean ( \pm standard error) DEI was marginally lower for anthropogenic forest edges adjacent to relatively narrow linear corridors $(31 \pm 4 \mathrm{~m})$ than for those adjacent to larger disturbed areas $(37 \pm 7 \mathrm{~m})$. Edges adjacent to areas burned by fire ignited by humans exhibited greater mean DEI (71 \pm $13 \mathrm{~m})$ than those adjacent to areas burned by wildfire $(20 \pm 4 \mathrm{~m})$.

\section{Discussion}

As expected, there has been a dramatic increase in the number of studies on vegetation at forest edges in the past three decades, 
Table 2. Summary of primary, secondary, and tertiary vegetation responses to anthropogenic and natural forest edges.

\begin{tabular}{|c|c|c|c|c|c|c|c|c|c|}
\hline & \multicolumn{3}{|c|}{ Anthropogenic } & \multicolumn{3}{|c|}{ Natural induced } & \multicolumn{3}{|c|}{ Natural inherent } \\
\hline & $\mathrm{H}$ & $\mathrm{L}$ & ns & $\mathrm{H}$ & $\mathrm{L}$ & $\mathrm{ns}$ & $\mathrm{H}$ & $\mathrm{L}$ & $\mathrm{ns}$ \\
\hline Primary process & 19 & 1 & 3 & 5 & & & & & 1 \\
\hline Primary structure & 55 & 129 & 44 & 5 & 16 & 10 & 19 & 67 & 32 \\
\hline Dead trees ${ }^{b}$ & 21 & 10 & 2 & 4 & 2 & 2 & 1 & 2 & 8 \\
\hline Primary composition & 5 & 5 & 5 & & $\mathbf{1}$ & 2 & & 4 & $\mathbf{1}$ \\
\hline Secondary process & 26 & 5 & 7 & & 2 & 1 & 3 & 2 & 1 \\
\hline Secondary structure & 82 & 66 & 29 & 9 & 14 & 9 & 21 & 12 & 15 \\
\hline Tree regeneration $^{c}$ & 39 & 13 & 7 & 2 & 6 & 3 & 3 & 5 & 3 \\
\hline Shrubs & 14 & 8 & 4 & 3 & 2 & & 5 & 1 & 4 \\
\hline Forbs & 7 & 6 & 7 & 1 & & 3 & 4 & 1 & 5 \\
\hline Graminoids & 5 & 4 & 1 & 3 & & & 2 & 1 & \\
\hline Nonvascular plants & 7 & 15 & 4 & & 4 & 1 & 2 & & 1 \\
\hline Nonnative species ${ }^{f}$ & 42 & & 3 & & & 2 & 2 & & 2 \\
\hline Tertiary process & 8 & 3 & 2 & 2 & & & & & \\
\hline Browse damage & 8 & 3 & 2 & 2 & & & & & \\
\hline
\end{tabular}

Note: Response variables were identified as higher $(\mathrm{H})$, lower $(\mathrm{L})$, or not significant (ns) at the edge compared with the interior forest. Categories in boldface type are comprehensive and include all response variables related to primary processes (tree mortality and windthrow), primary structure (live tree density, basal area,

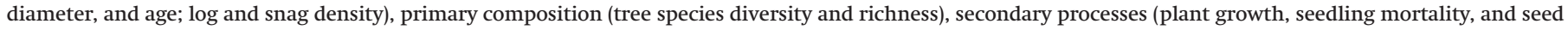

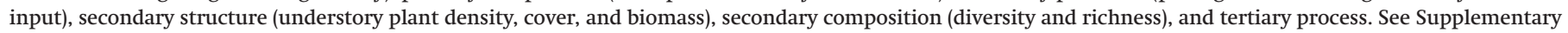
Tables S3 and S4 for more details. ${ }^{2}$

${ }^{a}$ Includes canopy tree cover, density, and abundance; total abundance, basal area, biomass, and stem density; total tree density and abundance; tree age, basal area, diameter, and height; and gap fraction.

${ }^{b}$ Includes snag density, coarse woody debris density, and coarse woody debris volume.

${ }^{c}$ Includes understory tree density, sapling density, seedling density, and seedling height.

${ }^{d}$ Excludes nonnative species.

${ }^{e}$ Excludes nonnative species.

${ }^{f}$ Includes nonnative species abundance, biomass, cover, and richness.

but this has not been consistent through time or space. Edge studies are still lacking in many developing regions globally as expected, but the number of studies has increased recently in South America and Asia. There have been fewer studies in sparse canopied forests, perhaps because edge influence is expected to be weaker, but that is changing with more studies in ecosystems such as cerrado or savanna in Brazil (Mendonça et al. 2015) and sparse oak (Quercus L.) forest in Iran (G. Valadi, J. Eshaghirad, Y. Khodakarami, M.N. Peykani, and K.A. Harper, unpublished data). Fewer studies in Africa, Oceania, and, until recently, Asia, are likely partly due to lower forest cover, yet there remain forested areas particularly in central Africa and most of Russia that are understudied, probably because of fewer resources for scientific research. Our results corroborate previous meta-analyses that revealed a geographical bias towards North America and Europe for ecological studies (e.g., Vellend et al. 2017).

Despite an overall global increase in edge studies over time, the number of studies on natural edges is low relative to that of anthropogenic edges, particularly in tropical forests. The difference may result from interests in the impacts of human activities on ecosystems for conservation, ease of access for sampling, or a greater abundance of anthropogenic edges, which has been documented on a national level in Sweden (Esseen et al. 2016). Our results indicate that natural forest edges can also be characterized by different vegetation than adjacent ecosystems and should therefore be considered in future studies. There was only a single study each on edge influence for forests adjacent to barrens, cliffs, dunes, and landslides. Some natural disturbances such as avalanches have yet to be considered in the context of edge influence on vegetation. The prominence of other edge types is related to their abundance in ecosystems (e.g., fire, insect outbreak, and recent clear-cut edges in boreal forest; pasture edges in tropical forest).

Our synthesis suggests that both anthropogenic and natural edges are dynamic features of heterogeneous landscapes. The findings revealed that greater tree damage at induced edges generally promotes changes in primary forest structure such as decreased basal area, tree density, and canopy cover at the edge compared with the forest interior. However, some of the maintained edge types (e.g., cropland, pasture, and urban) had greater canopy tree abundance at the edge than in the forest interior, probably due to better conditions and resources at the edge after a long period of establishment. Compared with interior forest, trees were younger at tree-line edges, possibly because of treeline advancement from the forest interior resulting from climate change, and at a forest-barren edge, where forest may be expanding towards the barren in a successional manner (Burley et al. 2010). Induced edges are not always maintained by human activity, as some natural induced edges were naturally maintained by high ungulate browsing at the forest edge (e.g., Franklin and Harper 2016). These edges could be at risk of forest recession, which also occurs because of repeated activities that hinder forest regeneration in maintained tropical anthropogenic edges (Gascon et al. 2000).

In addition to edge type, our synthesis suggests that forest type also affects edge influence. Forests in warmer latitudes generally had greater DEI estimates than colder boreal forests for both types of induced edges. The opposite trend for natural inherent edges was unexpected but seems to indicate more abrupt transi- 
Fig. 3. Mean distance of edge influence (DEI) on individual response variables investigated in natural and anthropogenic forest edge studies. Error bars represent maximum DEI. A total of 65 edges were considered from 56 studies. A detailed description of response variables by specific edge type (e.g., cropland and wetland) can be found in Supplementary Tables S5 and S6. ${ }^{2}$

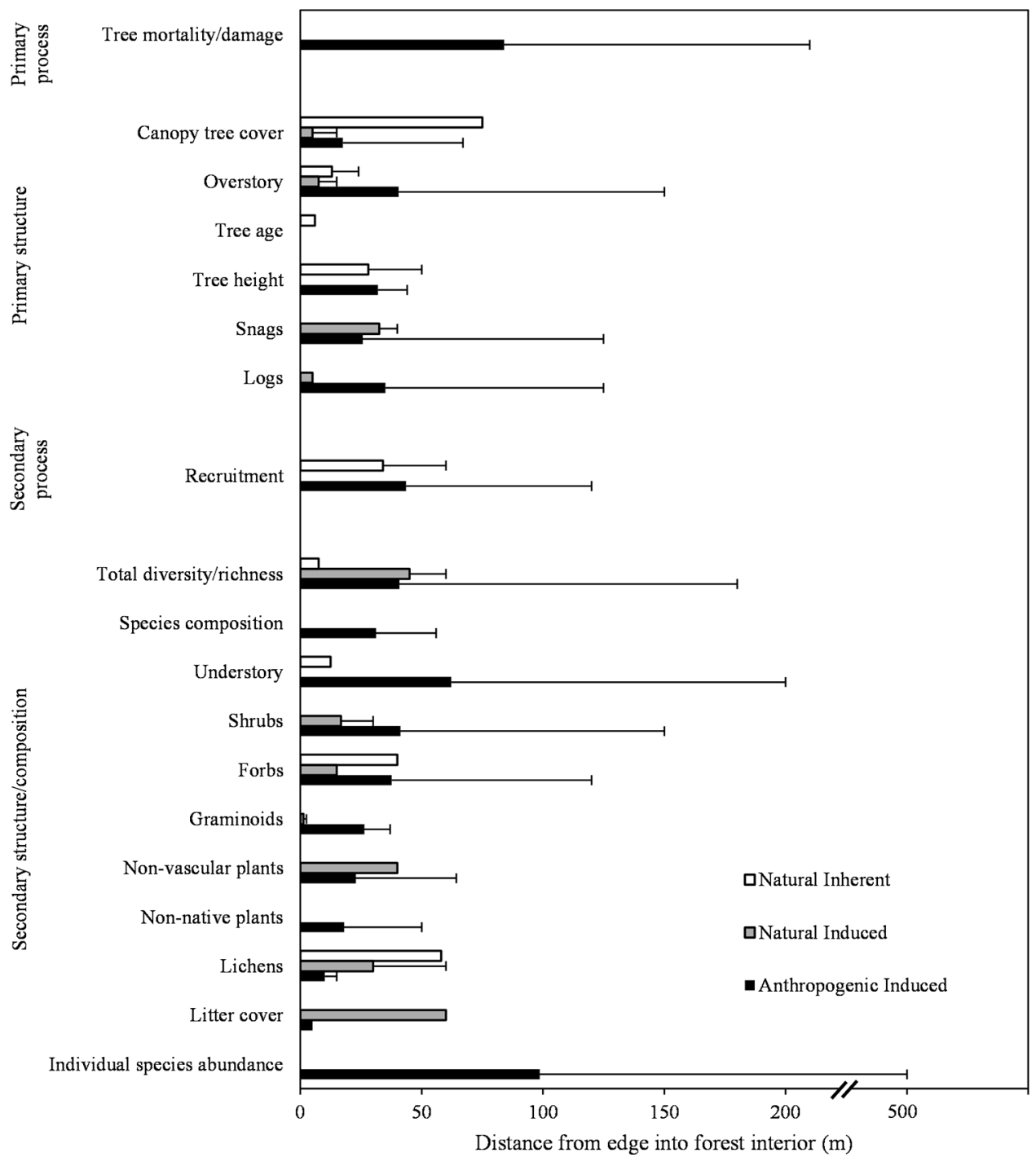

tion zones in temperate forests compared with broader gradual gradients across natural inherent edges in boreal forests.

Increased sapling density and understory cover common at many edges could be due to increased light availability at the forest edge, which could enhance the growth and development of shade-intolerant species (Chen et al. 1992). Increased light availability at forest edges could also contribute to the reduction in cover of light-sensitive lichens and mosses (Stewart and Mallik 2006). Increased species diversity at edges could result from higher levels of solar radiation, as well as wind speeds, which may promote seed dispersal to the forest edge (Hanson and Stuart 2005). As our findings indicated that a higher proportion of studies on inherent rather than induced natural edges revealed greater species diversity at the forest edge than in interior forest, the effects of two completely different ecosystems (inherent edges) may be more influential than dissimilarities in composition or structure (induced edges) on promoting high diversity at the forest edge; the plant communities on either side of induced edges may be considered the same ecosystem at different stages of succession. Increased diversity at the forest edge suggests that it may be a suitable habitat for species found on both sides of the interface (Erdös et al. 2013).

In accordance with our prediction, mean DEI was greater at anthropogenic edges than at both induced and inherent natural edges, for which it was similar. Greater overall edge effects on vegetation at anthropogenic edges than at natural edges could be influenced by differences in edge sealing, whereby dense vegetation develops at sharp edges maintained by human activity (Harper et al. 2005). The transition areas at natural edges could be more gradual than abrupt anthropogenic edges with greater contrasts between the forest and adjacent disturbed areas (Esseen et al. 2016). Forest management practices such as retention harvesting or restoration of linear corridors (e.g., pipelines and seismic lines) may reduce the contrast between adjacent ecosystems to help facilitate faster forest recovery after disturbance and minimize edge effects.

As predicted, DEI estimates for primary structural response variables were generally lower than those for secondary structure and composition. For example, DEI at forest-lakeshore edge was 10-30 m for live tree density (Komonen 2009) but was approxi- 
Fig. 4. Mean DEI on response variables investigated in tropical, temperate, and boreal forests at natural inherent, natural induced, and anthropogenic induced edges. Error bars represent maximum DEI. A total of 65 edges were considered from 56 studies. See Supplementary Tables S5 and S6 for additional details. ${ }^{2}$

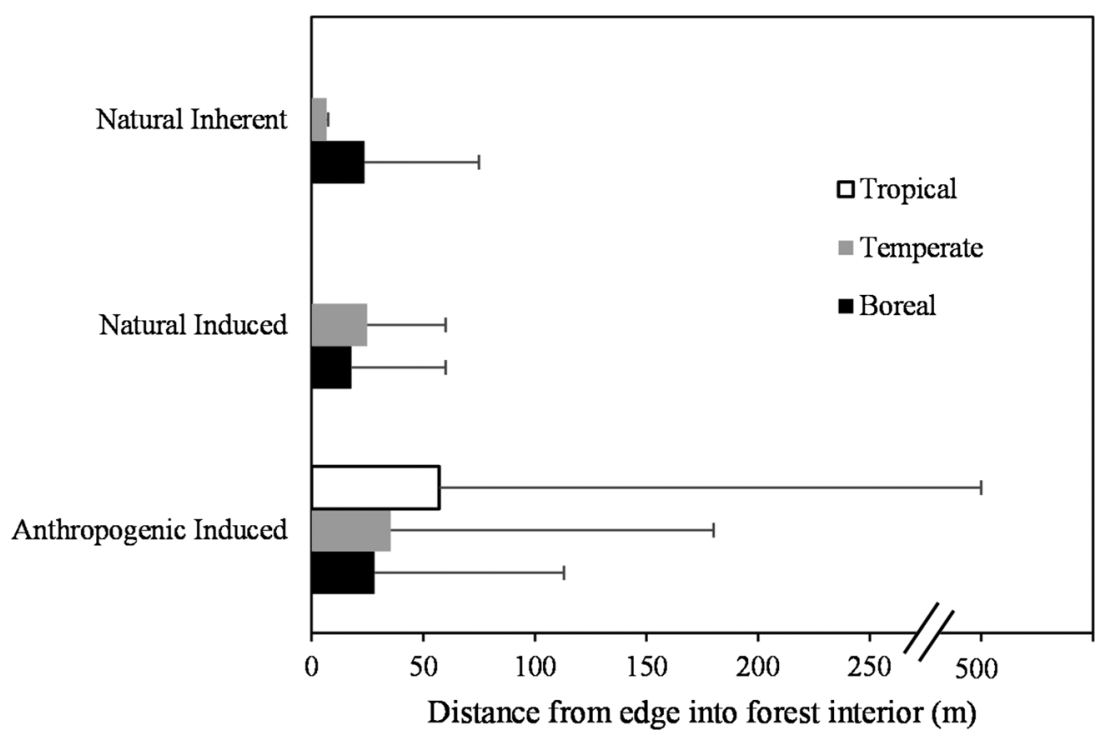

mately $40 \mathrm{~m}$ when considering understory responses such as saplings, shrub, and herb densities in addition to tree and coarse woody material densities (Harper and Macdonald 2001). Harper et al. (2005) demonstrated similar trends and claimed that secondary responses are caused by primary responses and consequently have delayed starts and longer durations. A review on microclimate found that DEI extended only $10-20 \mathrm{~m}$ into the forest (maximum $50 \mathrm{~m}$ ) (Schmidt et al. 2017). Detectable effects of changes in microclimate on vegetation are generally similar or even less; edge influence on plant communities may (Magnago et al. 2015) or may not (Mendonça et al. 2015) be due to microclimate.

It is important to understand mechanisms of edge influence; even a DEI of $20 \mathrm{~m}$ or less can be substantial in heavily fragmented landscapes (Riutta et al. 2014) or landscapes with large networks of linear corridors (Dabros et al. 2017). Because of fragmentation, most remaining global forest is less than $1 \mathrm{~km}$ away from an edge (Haddad et al. 2015). Taubert et al. (2018) predicts continuous forest loss with smaller fragments in the tropics. Our global review of edge studies can be useful for conservation, climate change research, and landscape ecology. For example, the amount of edge habitat on landscapes in England was linked to ecological responses based on DEI (Riutta et al. 2014).

Our synthesis of forest edge studies reveals several recommendations for future research. Researchers should explicitly state and describe their methods of sampling and data analyses. Comparisons of DEI between studies are problematic because DEI estimates can be influenced by the method of analysis (Harper and Macdonald 2011). A method used to estimate DEI that is invariable to sampling design, for example, the randomization test of edge influence (Harper and Macdonald 2011), could be an effective standard method of analysis that could contribute to the possibility of meta-analyses. We also encourage researchers to add more detailed descriptions of study areas and specify the size of the disturbed area adjacent to the edge, the age of the edge, and the history of anthropogenic activity. Studies on the interactive effects of multiple edges would enhance our understanding of edge effects on vegetation in highly fragmented areas.

Our review confirms that edge influence on vegetation depends on edge type, forest type, and response variable. Our review also suggests that both natural and anthropogenic forest edges are dynamic landscape features with unique vegetation attributes that can extend beyond the visible boundary, even at narrow linear corridors. Forest edges not only play important roles in the structure and function of ecosystems, but are also sensitive to climate change (Reinmann and Hutyra 2017; Hofmeister et al. 2019), so repeated sampling would provide insight into potential temporal changes in edge dynamics. As climate change is predicted to alter the dynamics of natural disturbances including wildfire and insect outbreaks, more quantitative studies on natural edges in particular could result in a meta-analysis that enhances our understanding of fragmented landscapes. Forest edge research has increasingly become an integral part of forest science scholarship. As forest fragmentation continues worldwide, we need a more global perspective on both anthropogenic and natural edges to better understand their ecological value and help inform management decisions for forest conservation.

\section{Acknowledgements}

We thank Kelsi Godin for her work on conducting some earlier literature searches and Anna Williams for creating Fig. 2. Funding was provided by the Natural Sciences and Engineering Research Council of Canada through a grant to K.A. Harper and the Government of Canada through Project Learning Tree Canada's Greenjobs program. We also acknowledge the role of supervision and training in forest science research. Our paper illustrates its impact, as S.E. Macdonald (Co-Editor-in-Chief) was the Ph.D. supervisor for both K.A. Harper and C.M.A. Franklin, and K.A. Harper was the M.Sc. supervisor for C.M.A. Franklin.

\section{References}

Braithwaite, N.T., and Mallik, A.U. 2012. Edge effects of wildfire and riparian buffers along boreal forest streams. J. Appl. Ecol. 49(1): 192-201. doi:10.1111/ j.1365-2664.2011.02076.x.

Burley, S.T., Harper, K.A., and Lundholm, J.T. 2010. Vegetation composition, structure and soil properties across coastal forest-barren ecotones. Plant Ecol. 211(2): 279-296. doi:10.1007/s11258-010-9789-7.

Cadenasso, M.L., Pickett, S.T., Weathers, K.C., and Jones, C.G. 2003. A framework for a theory of ecological boundaries. BioScience, 53(8): 750-758. doi:10.1641/0006-3568(2003)053[0750:AFFATO]2.0.CO;2.

Chen, J., Franklin, J.F., and Spies, T.A. 1992. Vegetation responses to edge environments in old-growth Douglas-fir forests. Ecol. Appl. 2(4): 387-396. doi:10.2307/1941873. 
Dabros, A., Hammond, H.E.J., Pinzon, J., Pinno, B., and Langor, D. 2017. Edge influence of low-impact seismic lines for oil exploration on upland forest vegetation in northern Alberta (Canada). For. Ecol. Manage. 400: 278-288. doi:10.1016/j.foreco.2017.06.030.

De Grandpré, L., Waldron, K., Bouchard, M., Gauthier, S., Beaudet, M., Ruel, J.-C., et al. 2018. Incorporating insect and wind disturbances in a natural disturbance-based management framework for the boreal forest. Forests, 9(8): 471. doi:10.3390/f9080471.

Erdős, L., Gallé, R., Bátori, Z., Papp, M., and Körmöczi, L. 2011. Properties of shrubforest edges: a case study from south Hungary. Cent. Eur. J. Biol. 6(4): 639-658. doi:10.2478/s11535-011-0041-9.

Erdős, L., Gallé, R., Körmöczi, L., and Bátori, Z. 2013. Species composition and diversity of natural forest edges: edge responses and local edge species. Commun. Ecol. 14(1): 48-58. doi:10.1556/ComEc.14.2013.1.6.

Erdős, L., Ambarli, D., Anenkhonov, O.A., Bátori, Z., Cserhalmi, D., Kiss, M., et al. 2018. The edge of two worlds: a new review and synthesis on Eurasian forest-steppes. Appl. Veg. Sci. 21(3): 345-362. doi:10.1111/avsc.12382.

Erdős, L., Krstonošić, D., Kiss, P.J., Bátori, Z., Tölgyesi, C., and Škvorc, Z. 2019. Plant composition and diversity at edges in a semi-natural forestgrassland mosaic. Plant Ecol. 220(3): 279-292. doi:10.1007/s11258-019-00913-4.

Esseen, P.-A., Ringvall, A.H., Harper, K.A., Christensen, P., and Svensson, J. 2016. Factors driving structure of natural and anthropogenic forest edges from temperate to boreal ecosystems. J. Veg. Sci. 27(3): 482-492. doi:10.1111/ jvs.12387.

Fardila, D., Kelly, L.T., Moore, J.L., and McCarthy, M.A. 2017. A systematic review reveals changes in where and how we have studied habitat loss and fragmentation over 20 years. Biol. Conserv. 212: 130-138. doi:10.1016/ j.biocon.2017.04.031.

Franklin, C.M.A., and Harper, K.A. 2016. Moose browsing, understorey structure and plant species composition across spruce budworm-induced forest edges. J. Veg. Sci. 27(3): 524-534. doi:10.1111/jvs.12385.

Gascon, C., Williamson, G.B., and da Fonseca, A.B. 2000. Receding forest edges and vanishing reserves. Science, 288(5470): 1356-1358. doi:10.1126/ science.288.5470.1356. PMID:10847849.

Haddad, N.M., Brudvig, L.A., Clobert, J., Davies, K.F., Gonzalez, A., Holt, R.D., et al. 2015. Habitat fragmentation and its lasting impact on Earth's ecosystems. Sci. Adv. 1(2): e1500052. doi:10.1126/sciadv.1500052. PMID:26601154.

Haddaway, N.R., and Pullin, A.S. 2014. The policy role of systemic reviews: past, present and future. Springer Sci. Rev. 2: 179-183. doi:10.1007/s40362014-0023-1.

Hanson, J.J., and Stuart, J.D. 2005. Vegetation responses to natural and salvage logged fire edges in Douglas-fir/hardwood forests. For. Ecol. Manage. 214(1-3): 266-278. doi:10.1016/j.foreco.2005.04.010.

Harper, K.A., and Macdonald, S.E. 2001. Structure and composition of riparian boreal forest: new methods for analyzing edge influence. Ecology, 82(3): 649-659. doi:10.1890/0012-9658(2001)082[0649:SACORB]2.0.CO;2.

Harper, K.A., and Macdonald, S.E. 2002. Structure and composition of edges next to regenerating clear-cuts in mixed-wood boreal forest. J. Veg. Sci. 13(4): 535-546. doi:10.1658/1100-9233(2002)013[0535:SACOEN]2.0.CO;2.

Harper, K.A., and Macdonald, S.E. 2011. Quantifying distance of edge influence: a comparison of methods and a new randomization method. Ecosphere, 2(8): art94. doi:10.1890/ES11-00146.1.

Harper, K.A., Lesieur, D., Bergeron, Y., and Drapeau, P. 2004. Forest structure and composition at young fire and cut edges in black spruce boreal forest. Can. J. For. Res. 34(2): 289-302. doi:10.1139/x03-279.

Harper, K.A., Macdonald, S.E., Burton, P.J., Chen, J.Q., Brosofske, K.D., Saunders, S.C., et al. 2005. Edge influence on forest structure and composition in fragmented landscapes. Conserv. Biol. 19(3): 768-782. doi:10.1111/ j.1523-1739.2005.00045.x.

Harper, K.A., Macdonald, S.E., Mayerhofer, M.S., Biswas, S.R., Esseen, P.-A., Hylander, K., et al. 2015. Edge influence on vegetation at natural and anthropogenic edges of boreal forests in Canada and Fennoscandia. J. Ecol. 103(3): 550-562. doi:10.1111/1365-2745.12398.

Hauck, M., de Bruyn, U., Javkhlan, S., and Lkhagvadorj, D. 2014. Forest edge-interior differentiation in the epiphytic lichen diversity of the forest steppe in the Khangai Mountains, Mongolia. J. Plant Ecol. 7(3): 287297. doi:10.1093/jpe/rtt033.

Hofmeister, J., Hošek, J., Brabec, M., Střalková, R., Mýlová, P., Bouda, M., et al. 2019. Microclimate edge effect in small fragments of temperate forests in the context of climate change. For. Ecol. Manage. 448: 48-56. doi:10.1016/j.foreco.2019.05.069.

Holland, M.M. 1988. SCOPE/MAB technical consultations on landscape boundaries: report of a SCOPE/MAB workshop on ecotones. In A new look at ecotones: emerging international project on landscape boundaries, Paris, France, 5-7 January 1987. Edited by F. di Castri, A.J. Hansen, and M.M. Holland. Biol. Intl. IUBS, Paris, France. pp. 47-106.

Kellman, M., Tackaberry, R., Brokaw, N., and Meave, J. 1994. Tropical gallery forests. Natl. Geog. Res. Explor. 10(1): 92-103.
Komonen, A. 2009. Forest characteristics and their variation along the lakeshore-upland ecotone. Scand. J. For. Res. 24(6): 515-526. doi:10.1080/ 02827580903280079.

Larrivée, M., Drapeau, P., and Fahrig, L. 2008. Edge effects created by wildfire and clear-cutting on boreal forest ground-dwelling spiders. For. Ecol. Manage. 255(5-6): 1434-1445. doi:10.1016/j.foreco.2007.10.062.

Laurance, W.F. 1991. Edge effects in tropical forest fragments: application of a model for the design of nature reserves. Biol. Conserv. 57(2): 205-219. doi:10.1016/0006-3207(91)90139-Z.

Laurance, W.F., Ferreira, L.V., Rankin-de Merona, J.M., and Laurance, S.G. 1998. Rain forest fragmentation and the dynamics of Amazonian tree communities. Ecology, 79(6): 2032-2040. doi:10.1890/0012-9658(1998)079 [2032:RFFATD]2.0.CO;2.

Magnago, L.F.S., Rocha, M.F., Meyer, L., Martins, S.V., and Meira-Neto, J.A.A. 2015. Microclimatic conditions at forest edges have significant impacts on vegetation structure in large Atlantic forest fragments. Biodivers. Conserv. 24(9): 2305-2318. doi:10.1007/s10531-015-0961-1.

Malcolm, J.R., Valenta, K., and Lehman, S.M. 2017. Edge effects in tropical dry forests of Madagascar: additivity or synergy? Landsc. Ecol. 32(2): 327341. doi:10.1007/s10980-016-0453-z.

Mendonça, A.H., Russo, C., Melo, A.C.G., and Durigan, G. 2015. Edge effects in savanna fragments: a case study in the Cerrado. Plant Ecol. Divers. 8(4): 493-503. doi:10.1080/17550874.2015.1014068.

Paiva, A.O., Silva, L.C.R., and Haridasan, M. 2015. Productivity-efficiency tradeoffs in tropical gallery forest-savanna transitions: linking plant and soil processes through litter input and composition. Plant Ecol. 216(6): 775-787. doi:10.1007/s11258-015-0466-8.

Pullin, A.S., and Knight, T.M. 2009. Doing more good than harm - building an evidence-base for conservation and environmental management. Biol. Conserv. 142(5): 931-934. doi:10.1016/j.biocon.2009.01.010.

Ranney, J.W., Bruner, M.C., and Levenson, J.B. 1981. The importance of edge in the structure and dynamics of forest islands. In Ecological studies: forest island dynamics in man-dominated landscapes. Edited by R.L. Burgess, D.M. Sharpe, and M.C. Bruner. Springer-Verlag, New York. pp. 67-95.

Reinmann, A.B., and Hutyra, L.R. 2017. Edge effects enhance carbon uptake and its vulnerability to climate change in temperate broadleaf forests. Proc. Natl. Acad. Sci. U.S.A. 114(1): 107-112. doi:10.1073/pnas.1612369114. PMID:27994137.

Risser, P.G. 1993. Ecotones at local to regional scales from around the world. Ecol. Appl. 3(3): 367-368. doi:10.2307/1941904. PMID:27759243.

Riutta, T., Slade, E.M., Morecroft, M.D., Bebber, D.P., and Malhi, Y. 2014. Living on the edge: quantifying the structure of a fragmented forest landscape in England. Landsc. Ecol. 29(6): 949-961. doi:10.1007/s10980-0140025-z.

Sala, O.E., and Maestre, F.T. 2014. Grass-woodland transitions: determinants and consequences for ecosystem functioning and provisioning services. J. Ecol. 102(6): 1357-1362. doi:10.1111/1365-2745.12326.

Sassen, M., and Sheil, D. 2013. Human impacts on forest structure and species richness on the edges of a protected mountain forest in Uganda. For. Ecol. Manage. 307: 206-218. doi:10.1016/j.foreco.2013.07.010.

Schmidt, M., Jochheim, H., Kersebaum, K.C., Lischeid, G., and Nendel, C. 2017. Gradients of microclimate, carbon and nitrogen in transition zones of fragmented landscapes - a review. Agric. For. Meteorol. 232: 659-671. doi:10.1016/j.agrformet.2016.10.022.

Stewart, K.T., and Mallik, A.U. 2006. Bryophyte responses to microclimatic edge effects across riparian buffers. Ecol. Appl. 16(4): 1474-1486. doi:10.1890/1051-0761(2006)016[1474:BRTMEE]2.0.CO;2. PMID:16937812.

Stockdale, C., Flannigan, M., and Macdonald, E. 2016. Is the END (emulation of natural disturbance) a new beginning? A critical analysis of the use of fire regimes as the basis of forest ecosystem management with examples from the Canadian western Cordillera. Environ. Rev. 24(3): 233-243. doi:10.1139/er-2016-0002.

Suzuki, S.N., Tomimatsu, H., Oishi, Y., and Konno, Y. 2013. Edge-related changes in tree communities in the understory of mesic temperate forest fragments of northern Japan. Ecol. Res. 28(1): 117-124. doi:10.1007/s11284012-0995-8.

Taubert, F., Fischer, R., Groeneveld, J., Lehmann, S., Müller, M.S., Rödig, E., et al. 2018. Global patterns of tropical forest fragmentation. Nature, 554(7693): 519-522. doi:10.1038/nature25508. PMID:29443966.

Thomas, J.W., Maser, C., and Rodiek, J.E. 1979. Edges. In Wildlife habitats in managed forests: the Blue Mountains of Oregon and Washington. USDA Agric. Handb. 553. Edited by J.W. Thomas. U.S. Department of Agriculture Forest Service, Portland, Ore. pp. 48-59.

Vellend, M., Dornelas, M., Baeten, L., Beauséjour, R., Brown, C.D., De Frenne, P., et al. 2017. Estimates of local biodiversity change over time stand up to scrutiny. Ecology, 98(2): 583-590. doi:10.1002/ecy.1660. PMID:27864922.

Wales, B. 1972. Vegetation analysis of northern and southern edges in a mature oak-hickory forest. Ecol. Monogr. 42(4): 451-471. doi:10.2307/1942167. 
Copyright of Canadian Journal of Forest Research is the property of Canadian Science Publishing and its content may not be copied or emailed to multiple sites or posted to a listserv without the copyright holder's express written permission. However, users may print, download, or email articles for individual use. 